EPJ Web of Conferences 114, 02106 (2016)

DOI: $10.1051 /$ epjconf/201611402106

(C) Uwned by the authors, published by EDP Sciences. 2016

\title{
Numerical and Experimental Study of a Cooling for Vanes in a Small Turbine Engine
}

\author{
Jan Šimák ${ }^{1, a}$ and Jan Michálek ${ }^{1}$ \\ ${ }^{1}$ Aerospace Research and Test Establishment, Prague
}

\begin{abstract}
This paper is concerned with a cooling system for inlet guide vanes of a small turbine engine which are exposed to a high temperature gas leaving a combustion chamber. Because of small dimensions of the vanes, only a simple internal cavity and cooling holes can be realized. The idea was to utilize a film cooling technique. The proposed solution was simulated by means of a numerical method based on a coupling of CFD and heat transfer solvers. The numerical results of various scenarios (different coolant temperature, heat transfer to surroundings) showed a desired decrease of the temperature, especially on the most critical part - the trailing edge. The numerical data are compared to results obtained by experimental measurements performed in a test facility in our institute. A quarter segment model of the inlet guide vanes wheel was equipped with thermocouples in order to verify an effect of cooling. Despite some uncertainty in the results, a verifiable decrease of the vane temperature was observed.
\end{abstract}

\section{Introduction}

Modern turbine engines are very sophisticated machines designed to transform energy into mechanical work as efficiently as possible. A desired high level of the efficiency is connected with high temperatures and pressures that thermally and mechanically strain turbine components. The present-day aircraft engines often operate close or above melting point of the used material and therefore require an intensive heat protection.

The most common and simplest way to reduce temperature to safe values is the use of cold air [1]. A combination of an internal and film cooling is a typical example of this approach. An amount of the air used for the active cooling may reach up to twenty percent of the entire engine core mass flow [2], which in turn somewhat reduces achieved thermal efficiency. However, a gain from the increased working temperature is still higher than losses. The mentioned approach is sometimes combined with a thermal barrier coating (TBC) applied on the most stressed surfaces to extend the component lifespan.

The internal cooling system usually consists of a complicated labyrinth of channels, turbulizators, pins and cavities inside the vane, which distributes the coolant through the body in order to transfer the excessive heat away. The film cooling is achieved through a formation of a thin layer of 'cold' air uniformly distributed over the surface which provides an insulating thermal barrier against the hot gas of the bulk flow. This is usually accomplished by a large quantity of shaped and optimized holes connecting the internal channels with the vane surface.

\footnotetext{
${ }^{\mathrm{a} C}$ Corresponding author: simak@vzlu.cz
}

The problem of cooling is even more challenging in small engines due to their dimensions and compact design. Moreover, the most stressed parts, such as vanes and blades of a gas generator, are often surrounded by an annular combustion chamber which prevents the heat to conduct away. The inlet guide vanes (IGV) of the studied engine are not presently cooled and suffer from an extensive heat degradation mainly in the vicinity of the trailing edge. An initial attempt considered a simple vane film cooling introduced from a slit tube in the leading edge region $[3,4]$. However, the obtained results were found questionable and this concept was abandoned. For the above reasons, a new IGV profile was proposed taking in account an internal cavity and several cooling holes deployed at the rear part of the pressure side. This novel concept was examined within the presented work.

The problem was at first studied by means of threedimensional numerical simulations, which provided a good preview of the situation and of the impact of the suggested solution. The simulations were performed by a CFD solver based on the Reynolds averaged NavierStokes equations (RANS) and a solver for a heat conduction in a solid. The obtained results showed a feasibility of the adopted concept which was further verified by conducted experiments.

\section{Description of the problem}

The problem considered in this work is an initial study of an IGV cooling system for a gas generator of turbine engines intended for light aircraft. The small dimensions of the engine (maximum outer diameter is about 
$270 \mathrm{~mm}$ ) and of the IGV wheel (the hub and shroud radii are $50 \mathrm{~mm}$ and $69.75 \mathrm{~mm}$ ) and also its counter flow combustion chamber arrangement (see figure 1) strongly limit any practicable design variants of a cooling system. Moreover, due to the small size of the vanes, it would be very difficult to create a sophisticated system of internal channels that distribute cooling air. Limiting were also the aspects regarding the cost and technological complexity related to an application of a TBC. The engine parts are manufactured from nickel-chrome super-alloys (e.g. Inconel 713 or 718 ).

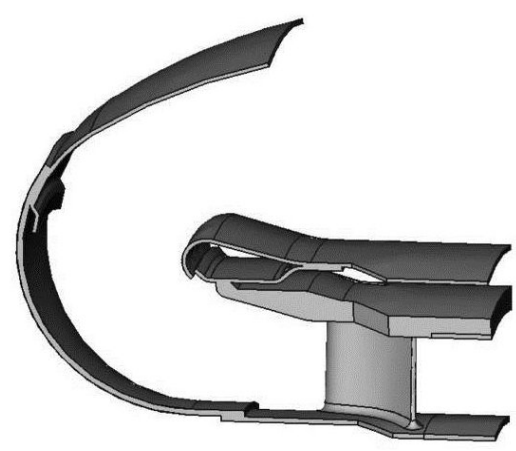

Figure 1. A complete CAD model of the IGV section with an exit from a combustion chamber.

From these reasons, a simple concept of an active fluid cooling was introduced. A practical experience showed that the most critical part of the vane regarding the thermal strain was the trailing edge region mainly at the vane mid-height. Therefore, an emphasis was put on this area during a design phase. According to preliminary numerical simulations performed with a uniform temperature distribution of the incoming air, temperatures at the trailing edge region exceeded $930{ }^{\circ} \mathrm{C}$. In a case of a non-uniform distribution, temperature could possibly grow even higher.

Because of the above mentioned reasons, it was decided to create a simple internal cavity situated in the thickest part of the vane with seven cooling holes leading to the pressure side. The main idea was to decrease the vane temperature by the heat exchange with the cold air inside the cavity and by forming a thin film layer protecting the most critical part on the trailing edge. This solution was however allowed only by a redesign of the vane profile which was supplied by the producing company. The new profile was enlarged to allow the cavity and the trailing edge was thickened to reduce the heat corrosion. As a result, the redesigned IGV wheel consists of only 17 vanes, while the original one has 26 vanes.

An overview of the basics concerning the film cooling can be found e.g. in [5]. It is well known that the position, direction and shape of holes influence the overall efficiency but we tried to suggest a simple solution. Thus the holes are of a cylindrical shape and in a small number. The tested cooling system consists of an oval shaped cavity which opens into an annular channel next to the shroud. A cooling medium, which is a cold compressed air diverted before reaching the combustion chamber, flows through this channel. Further, this cold air is brought from inside of the cavity to the surface of the pressure side of the vane by seven cooling holes. These holes are parallel to each other, each of them has a circular cross-section with a diameter $d=0.8 \mathrm{~mm}$ and are spaced two diameters apart. The central cooling hole is positioned slightly above the mean radius of the wheel and the openings are located on the surface in about one third of the vane from the trailing edge. The cooling channels are designed such that the middle one is inclined $30^{\circ}$ to the surface. The axes of the cooling channels are also tilted with respect to the stator wheel axis with a compound angle of $30^{\circ}$. The configuration is shown in figure 2 .

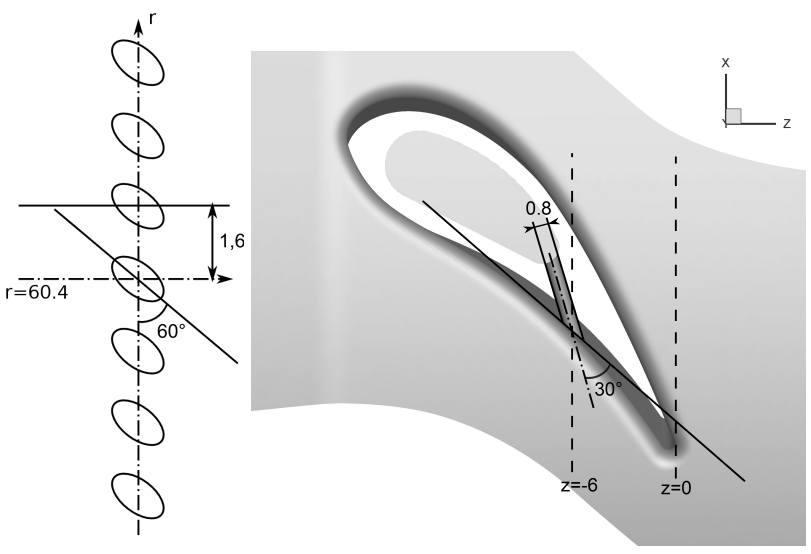

Figure 2. Geometry of the vane cooling channels: meridional plane (left), tangential plane (right).

\section{Numerical methods}

From a numerical point of view, the problem was solved as two separated problems coupled by a common boundary. An iterative process (called outer in this text) then provided an exchange of information between a CFD solver and a heat solver.

\subsection{Solution of the flow problem}

We considered a steady, compressible flow of a perfect gas (for simplicity air), described by the three-dimensional RANS equations. The problem was solved using the CFD software Edge v5.2, which is based on a finite volume method on dual meshes. The presented results were obtained by the use of an upwind scheme with the Roe averaging of state variables on cell faces. To increase spatial order of accuracy, a reconstruction of variables on the cell faces (symmetric TVD scheme) was applied. Since the flow was transonic and contained shock waves, the minmod limiter was used to suppress undesirable numerical oscillations near flow discontinuities.

The governing equations were integrated in a time variable to a stationary solution using an explicit threestage Runge-Kutta method with a local time step. To accelerate the convergence, a multigrid and an implicit residual smoothing were involved. 
The flow was modelled as fully turbulent with an EARSM k- $\omega$ turbulence model proposed by Hellsten [6], which is also the default choice of Edge. More information about the solver can be found in [7].

A weak pressure condition, which prescribes the overall state variables - total pressure, total temperature and flow direction, was chosen as a boundary condition at the main inlet and also at the entrance to the cavity. At the outlet boundary there was prescribed an integral average of a static pressure. Walls were treated either as adiabatic or with a prescribed wall temperature obtained from the heat solver.

The source code of the software used in this study was slightly modified compared to the original version, namely the boundary conditions were adapted for problems of internal aerodynamics and procedures, which were necessary for coupling with a heat solver, were added.

A flow field with adiabatic walls was taken as an initial condition for the heat transfer problem. Further, at each step of the outer iteration process inner iterations (up to 20) were performed to get a new thermal boundary profile that corresponded to new wall temperatures.

\subsection{Mesh generation}

The shape of a computational domain was derived from a simplified geometry without considering a rotor. The domain was a periodic part containing one vane and relevant parts of channels between vanes. The outlet boundary was extended further behind the trailing edge from reasons to prevent possible reflections from this boundary. The shape of hub and shroud walls was also slightly simplified.

The computational domain was discretized by a multiblock structured grid, created by the GridPro software. The computational domain thus consisted of blocks with six-sided cells. The grids for the flow and heat conduction problem were generated separately. Since cells of the inner and outer grids are not necessarily linked one to one, an interpolation matrix was constructed, which maps surface vertices from one grid to the other grid and vice versa. The shape of periodic boundaries was determined by the grid generator automatically.

In order to properly capture a profile of a boundary layer in the simulation, the height of the first row of cells on walls was chosen such that $y^{+} \leq 1$ based on the expected velocity. The number of cells in the grid was approximately $7 \cdot 10^{6}$ for a simple vane and $8.5 \cdot 10^{6}$ for the vane with the cooling system.

\subsection{Solution of the heat conduction}

The heat conduction in the vane and in connecting hub and shroud walls was performed using an in-house software for a solution of a heat equation. This equation has the form of

$$
c \rho \frac{\partial T}{\partial t}-\operatorname{div}(\lambda \nabla T)=0,
$$

where $T$ is the temperature, $c$ heat capacity, $\rho$ density and $\lambda$ thermal conductivity. The equation was discretized by a finite volume method on a multi-block structured grid and integrated towards a steady state by the backward Euler scheme.

At parts of the boundary, which are common to the solid body and the flow field, a heat transfer boundary condition was considered. This condition is based on the Fourier's law $\mathbf{q}=-\lambda \nabla T$ for a local heat flux $\mathbf{q}$ and equality of the heat fluxes from both sides of the boundary. So the boundary condition can be formulated as

$$
\lambda \frac{\partial T}{\partial n}=\lambda_{a} \frac{T_{a}-T}{d_{a}},
$$

where $\mathbf{n}$ is the outer unit normal vector, $\lambda_{a}$ the thermal conductivity of the air, $T_{a}$ temperature of the air in the first row of nodes and finally $d_{a}$ denotes the distance of these nodes to the wall.

The periodic boundary condition ensures then the portability of obtained results to the whole IGV wheel geometry.

\section{Numerical results}

\subsection{Setting up the problem}

The engine IGV wheel was made from a nickel-chrome alloy Inconel 713LC which has the thermal conductivity $\lambda=20 \mathrm{~W} \mathrm{~m}^{-1} \mathrm{~K}^{-1}$ at $760{ }^{\circ} \mathrm{C}$. The heat capacity at the same temperature is $c=625 \mathrm{~J} \mathrm{~kg}^{-1} \mathrm{~K}^{-1}$, the values of $\lambda$ and $c$ are changing with temperature. The melting point of the material is around $1260{ }^{\circ} \mathrm{C}$.

The total pressure and total temperature at the inlet to the IGV wheel were

$$
P_{01}=476.481 \mathrm{kPa}, T_{01}=950^{\circ} \mathrm{C} \text {. }
$$

The coolant total pressure and total temperature were set to

$$
P_{0 c}=495.015 \mathrm{kPa}, T_{0 c}=210{ }^{\circ} \mathrm{C}-470{ }^{\circ} \mathrm{C} \text {. }
$$

The integral average of the static pressure at the exit boundary was set to

$$
P_{2}=265.553 \mathrm{kPa} .
$$

The turbulence intensity of the incoming air was set to $T u=3 \%$. The flow field entering the computational domain was assumed homogeneous and perpendicular to the boundary. The isentropic Mach number behind the IGV was $M_{2, i s}=0.95$.

\subsection{Vane cooling without heat transfer}

The first step was to evaluate the effect of the proposed cooling system and to find the best configuration. Hence the problem with adiabatic walls (e.g. no heat transfer to the vane) was solved. The temperature of the cooling air 
was set $T_{0 c}=210^{\circ} \mathrm{C}$. The effectiveness was evaluated in terms of the film effectiveness, $\eta$, defined as follows:

$$
\eta=\frac{T_{01}-T_{a w}}{T_{01}-T_{0 c}},
$$

where $T_{a w}$ refers to the adiabatic wall temperature. The distribution of $\eta$ on the vane surface is shown in figure 3. It is clearly seen that the holes do not create a continuous film of cold air that would completely insulate the surface from the hot air. To do this, one would need to use more holes in more rows or change the shape of the holes, which is in a contradiction with our requirements of simplicity and robustness. However, the area of the surface influenced by the cold air seemed to provide sufficient decrease of the trailing edge temperature. The mass flow rate of the cooling air entering to one vane was evaluated as $\dot{m}_{c}=0.00173 \mathrm{~kg} \mathrm{~s}^{-1}$, the mass flow rate at the main inlet was $\dot{m}=0.1074 \mathrm{~kg} \mathrm{~s}^{-1}$ per one period. That means the cooling air represented $1.59 \%$ of the total flow. The mass flow $\dot{m}_{c}$ is given by the number of holes and by the pressure drop between the entrance to the cavity and the vane pressure side near the hole exit location.

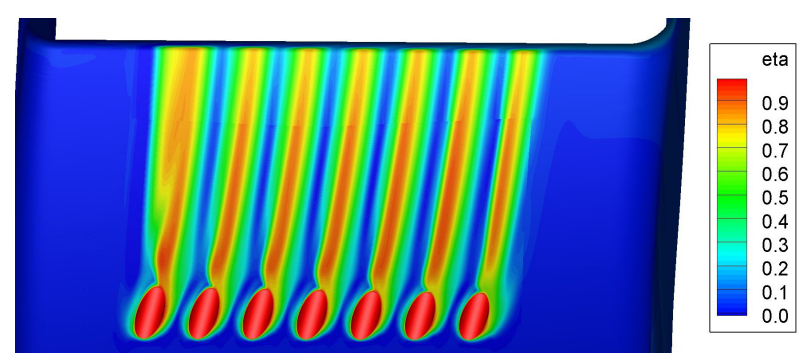

Figure 3. The film effectiveness on the adiabatic vane surface

\subsection{Vane cooling with heat transfer}

Further, the heat transfer model was accompanied into the simulations. It is very difficult to model the same situation as in a real engine because we have no information about heat fluxes through outer boundaries of our model. We do not even know the temperatures of these parts. Thus, we assumed a zero heat transfer on these outer boundaries. This means that we supposed the solid body was isolated from the surroundings. This approach is thought to be satisfactory for our purpose of evaluation of the cooling efficiency. However, the comparison with experimental data is more difficult. In the later simulations, this approach was partly abandoned to find out the influence of the surroundings.

Using the described method, a temperature distribution was obtained at first on a vane with no cooling (NC). At the trailing edge, an average temperature was $931.8^{\circ} \mathrm{C}$, while temperature of the incoming flow was $950{ }^{\circ} \mathrm{C}$. This result was then compared to a case when the vane is actively cooled with the inner cavity and cooling holes. When using the cooling air of a temperature $210{ }^{\circ} \mathrm{C}$, an average temperature at the trailing edge decreased to a value of $838.8^{\circ} \mathrm{C}$. That means reduction of $93^{\circ} \mathrm{C}$.

Comparing the results to a variant with only the inner cooling (with the same performance) present, we can express the effectiveness of the cold film. Figure 4 shows a decrease of the temperature up to $34{ }^{\circ} \mathrm{C}$ on the trailing edge. Moreover, this result is for the case with higher cooling air temperature, $T_{01}=910^{\circ} \mathrm{C}$ and $T_{0 c}=470{ }^{\circ} \mathrm{C}$.

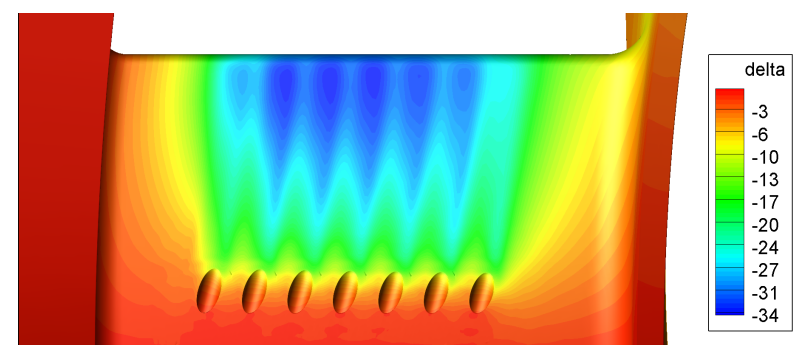

Figure 4. A temperature decrease due to the film cooling.

The maps of surface temperature for NC and cooling $\left(T_{0 c}=210^{\circ} \mathrm{C}\right)$ variants are presented in figure 5 . The injection is usually described by the blowing ratio defined as

$$
B R=\frac{\rho_{c} V_{c}}{\rho V}
$$

where $\rho$ and $V$ are the mainstream density and velocity above the holes, the momentum flux ratio

$$
I=\frac{\rho_{c} V_{c}^{2}}{\rho V^{2}}
$$

and the density ratio

$$
D R=\frac{\rho_{c}}{\rho} .
$$

The values for this case are $B R=1.098, I=0.58$ and $D R=2.07$. The cooling jets are located on a concave surface with a non-dimensional parameter $2 R / d=-69$ where $R$ denotes the curvature radius. These values indicate a regime that could lead to a decrease of the efficiency. The following figures 6 and 7 show shapes of the cooling jets. Because of the small number of holes and their spacing, the resulting cooling jets do not form a continuous thin film, but the individual jets remain isolated. The pictures show that the cross section of the jet is not homogeneous, but it has a shape of a horseshoe. That means the jet is not fully attached to the vane surface and the efficiency is lower than in a case of a fully attached flow. A more appropriate choice of the coolant holes configuration would certainly eliminate this imperfection.

The mass flow rate of the cooling air per one vane is $\dot{m}_{c}=0.00144 \mathrm{~kg} \mathrm{~s}^{-1}$ (corrected mass flow rate $\mathrm{Q}_{\mathrm{c}}=1.09$ $\mathrm{kg} \mathrm{s}^{-1} \mathrm{~K}^{1 / 2} \mathrm{MPa}^{-1}$ ). In comparison with the mass flow rate through the inlet boundary, which for one blade to blade channel attained a value of $\dot{m}=0.1074 \mathrm{~kg} \mathrm{~s}^{-1}\left(\mathrm{Q}_{\mathrm{c}}\right.$ $\left.=134.01 \mathrm{~kg} \mathrm{~s}^{-1} \mathrm{~K}^{1 / 2} \mathrm{MPa}^{-1}\right)$, it represented approximately $1.32 \%$ of the total mass flow. 

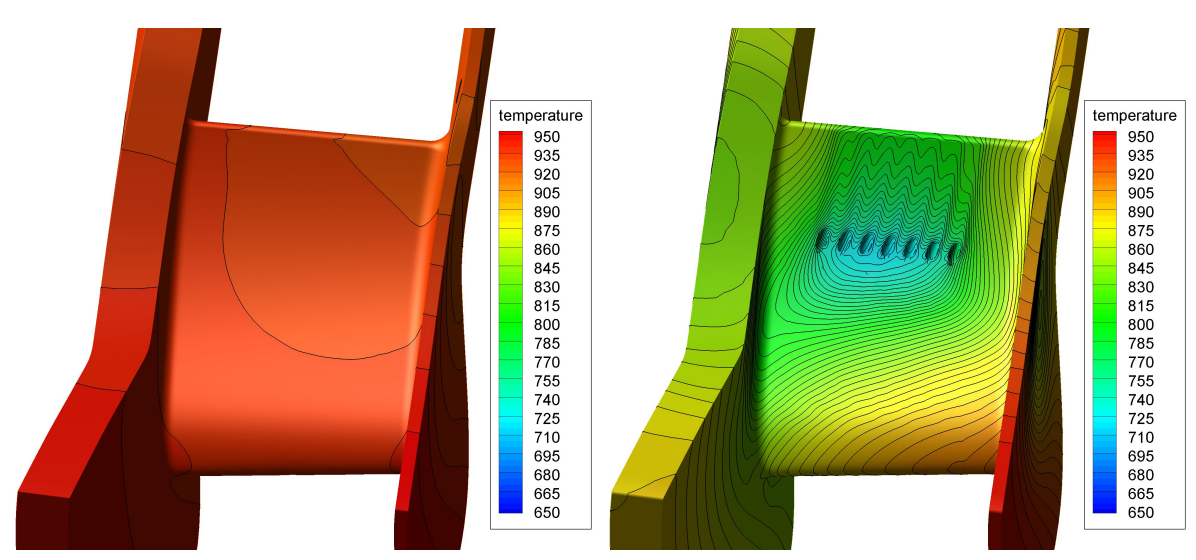

Figure 5. A distribution of temperature on the vane surface; uncooled (left), cooled (right); the coolant temperature $210^{\circ} \mathrm{C}$.

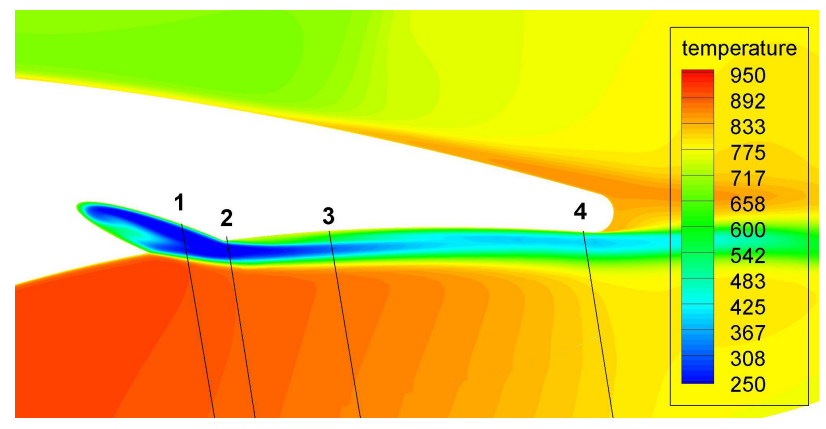

Figure 6. A section along the cool jet from the middle cooling hole with indicated positions of cross-sections.

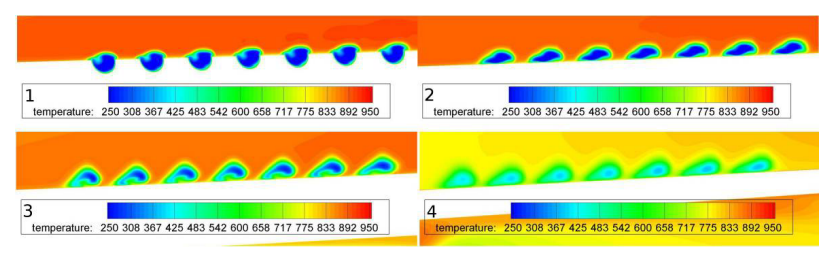

Figure 7. Cross-sections of the cool jets at given positions.

The calculated mass-weighted average values of the kinetic energy loss $\zeta$ and total pressure loss $\xi$, given as follows:

$$
\begin{array}{r}
P_{0, \text { mix }}=\frac{\dot{m}_{c}}{\dot{m}_{c}+\dot{m}} P_{0 c}+\frac{\dot{m}}{\dot{m}_{c}+\dot{m}} P_{01}, \\
M_{i s}=\sqrt{\left[\left(\frac{P_{0, m i x}}{P}\right)^{\frac{k-1}{\kappa}}-1\right] \frac{2}{\kappa-1},} \\
\zeta=1-M^{2} / M_{i s}^{2}, \\
\xi=1-P_{0} / P_{0, m i x},
\end{array}
$$

where $M$ denotes the Mach number. The values at a distance of $5 \mathrm{~mm}$ behind the trailing edge are presented in table 1 . The resulting temperature on the trailing edge is presented in figure 8 .
Table 1. The loss coefficients of the uncooled and cooled IGV.

\begin{tabular}{lcc}
\hline & $\zeta$ & $\xi$ \\
$\mathrm{NC}$ & 0.0518 & 0.0286 \\
Cooling $T_{0 c}=210^{\circ} \mathrm{C}$ & 0.0521 & 0.0289 \\
Cooling $T_{0 c}=410^{\circ} \mathrm{C}$ & 0.0532 & 0.0294 \\
\hline
\end{tabular}
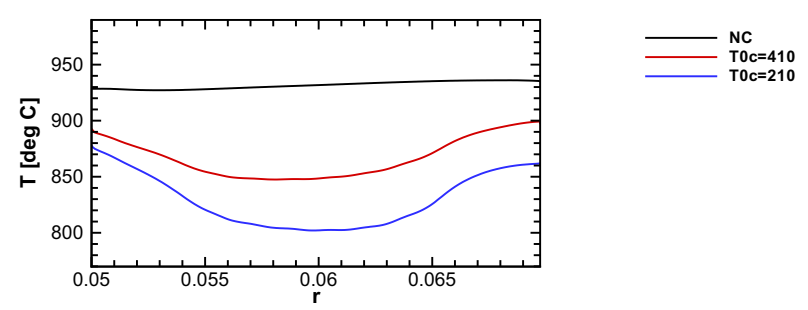

Figure 8. A distribution of the trailing edge temperature plotted along the radius.

\subsection{Vane cooling with heat transfer through tip shroud}

Looking at the figure 1 it is possible to take notice of the annular channel bringing the cooling air to the vane. Since the coolant flows around this wall, it is correct to expect some heat transfer through this boundary. The variants with a prescribed coolant temperature of 210, 310, 410 and $470{ }^{\circ} \mathrm{C}$ were evaluated. The latter variant for coolant temperature $470{ }^{\circ} \mathrm{C}$ was evaluated with a different inlet boundary condition. Profiles of the total pressure and total temperature were prescribed on the inlet boundary according to data obtained by the experiments. The inlet temperature at the inner radius was $876.6^{\circ} \mathrm{C}$ and at the outer radius $932.75{ }^{\circ} \mathrm{C}$. The average total temperature $T_{01}=910{ }^{\circ} \mathrm{C}$, the total pressure remained the same. This variant was thus closest to the experimental data. However, the numerical model still differs from the experimental model because we have no information about the heat transfer through outer boundaries.

When we therefore considered a heat transfer through the tip shroud, we observed a decrease of the temperature 
in this area. A comparison of a temperature on the trailing edge for the considered variants is in figure 9.

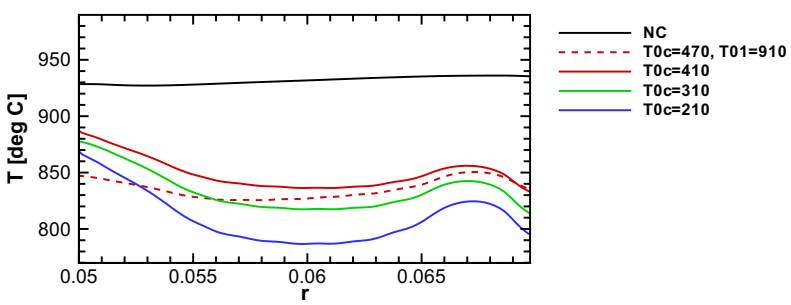

Figure 9. A distribution of the trailing edge temperature plotted along the radius. Considered is a heat transfer through the tip shroud; $T_{01}=950^{\circ} \mathrm{C}$.

\section{Experimental evaluation}

\subsection{Test facility}

An experimental verification of the proposed cooling system was carried out on a test rig consisted of three principal parts: radial compressor ( $\mathrm{RC}$ ), combustion chamber (CC) and tested IGV segment. An amount of the air supplied by the radial compressor at desired pressure was restricted by its working regime and therefore only a quarter segment of the combustion chamber and of the IGV model was considered in the test rig. Considering the proposed number of the vanes (17), the test model resulted in an annular segment with only four blade to blade channels, i.e. three full vanes. Due to the technological purposes a nickel-chrome alloy Inconel $713 \mathrm{LC}$, used in the serial production, was substituted with Inconel 718 which has similar physical properties as the original material. Three alternative IGV segments were used within the experimental campaign: a variant without cooling (IGV-NC), one with an internally delivered cooling (IGV-IC) and one with an externally delivered cooling (IGV-EC). The IGV-NC segment served as a reference for a comparison with the other two cooled segments. A scheme of the test rig with alternative cooling arrangements supplied with measured parameters is presented in figure 10.

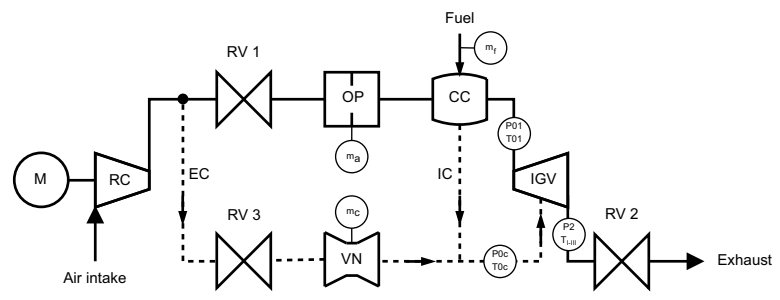

Figure 10. A scheme of the test rig with two alternative cooling arrangements; a) internally delivered coolant (IC), b) externally delivered coolant (EC).

The IGV-IC (figure 11) variant represented a real engine configuration with three hollow vanes and seven cooling holes located on the pressure side of each vane. The variant utilized the coolant (mostly compressed air) from a space between the combustion chamber and the outer diameter of the IGV wheel. The mass flow rate of the coolant was given by prescribed flow parameters and by an effective flow area of the cooling holes.

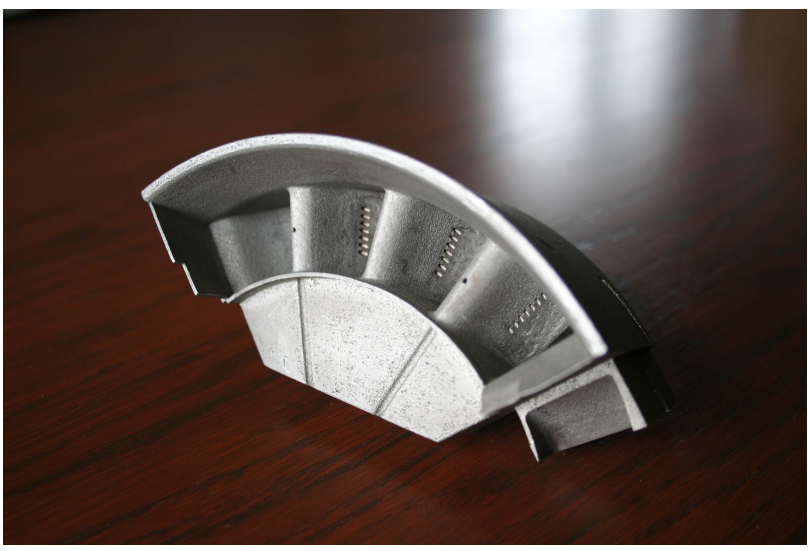

Figure 11. The IGV-IC segment. An inlet view with the cooling channels on the vanes pressure sides.

Finally, the IGV-EC configuration allowed us to control an amount of the coolant air delivered to the vane internal cavity from an external source. The air was taken at the compressor exhaust and delivered to each of the internal vane cavity through a single air distributor welded to the hub block. The opposite ends of the vane internal cavities were blinded. An amount of the cooling air was controlled through the regulating valve and the actual value was measured by means of a calibrated Venturi nozzle (figure 10).

\subsection{IGV probes instrumentation}

All the three IGV segments were equipped with thermocouple probes and pressure probes. The vane metal temperature was monitored by means of three unshielded Ktype thermocouples installed into the trailing edge region of the three individual vanes. They were flush-mounted into the pre-machined groves at vanes mid-height using a high-temperature resistant cement. The thermal conductivity of the cement was slightly higher than the base material Inconel 718. The total pressure $\left(\mathrm{P}_{0 \mathrm{c}}\right)$ and total temperature $\left(\mathrm{T}_{0 \mathrm{c}}\right)$ of the coolant were in the case of IGV-EC arrangement monitored by means of a Pitot probe and a T-type thermocouple probe placed in the supply pipe just before the IGV entry. In the case of IGV-IC configuration, the total temperature and pressure readings were provided by means of a shielded K-type thermocouple and a stainless-steel tube installed inside one of the vane internal cavities.

\section{Experimental results}

\subsection{IGV segment without cooling}

Tests on the uncooled IGV segment were performed for a range of flow regimes characterized by the exit isentropic 
Mach number. The inlet total temperature was held approximately constant on a value of $850{ }^{\circ} \mathrm{C}$.

The air mass flow rate, as measured on the orifice plate, increased together with the higher Mach number until eventually conditions close to the choking were reached for desired pressure ratio $P_{2} / P_{01}=0.557, P_{01}=$ $476.481 \mathrm{kPa}, P_{2}=265.553 \mathrm{kPa}$.

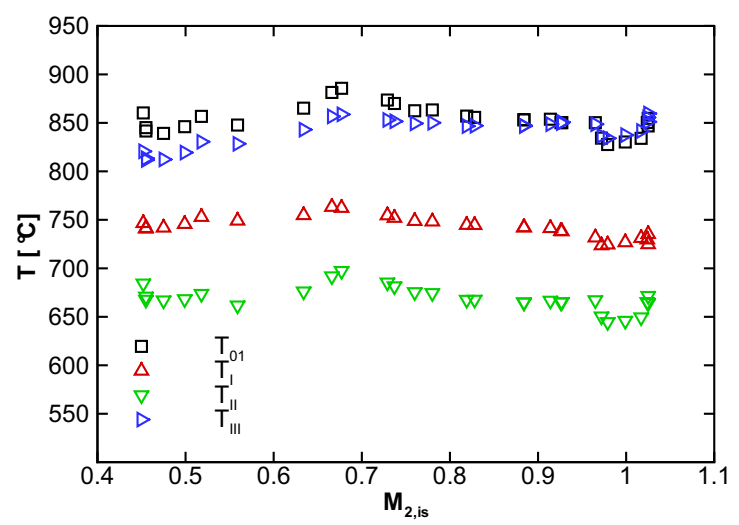

Figure 12. IGV-NC - the inlet total temperature and the trailing edge metal blade temperatures as a function of the exit isentropic Mach number.

Relatively large temperature differences were measured between the thermocouple probes installed in the individual vanes as presented in figure 12. While the two probes placed at the same vane (III) showed virtually same temperatures $\left(\mathrm{T}_{01}, \mathrm{~T}_{\text {III }}\right)$, the other two neighbouring vanes exhibited significantly lower values. A temperature difference between the vane III and II reached values as large as $200{ }^{\circ} \mathrm{C}$ despite the fact that preliminary tests in the duct behind the combustion chamber showed a satisfactorily uniform distribution of temperatures in the circumferential direction with an only slight variation along the vane height.

Given the above information and a fact that similar pattern was found also for the tests performed on the other two types of the IGV it was concluded that the temperature variation was systematic due to a temperature gradient and consequent heat transfer within the solid of the test section. The real engine configuration with an annular IGV shielded by a combustion chamber is, however, qualitatively different and it should be taken in account while interpreting the presented data.

\subsection{IGV segment with external coolant delivery}

The measurements on a variant of the IGV with the external coolant delivery (IGV-EC) were carried out in a narrow range of the exit isentropic Mach number close to unity. The pressures prescribed during the tests attained approximately the required boundary conditions (section 4.1). The total temperature at the inlet was set to a value near to $910^{\circ} \mathrm{C}$ in the beginning of the test.

An amount of the coolant through the IGV was during the test controlled by the RV3 valve from a fully closed state until a point when the mass flow did not change anymore. A ratio of the coolant and the main flow total pressures was ranging roughly between 0.88 and 1.02 and thus the maximal reached value was slightly below the required conditions, i.e. 1.038 .

A similar nature, as observed in the case of IGV$\mathrm{NC}$, regarding a temperature variation between individual vanes was found also for this type of the IGV segment (figure 13). For zero coolant mass flow the trailing edge temperature of the vane III was again akin to the total temperature which was measured at the leading edge of the same vane. The other two adjacent vanes I and II exhibited much lower values with a difference about $150{ }^{\circ} \mathrm{C}$ with respect to the vane III.

When the coolant is introduced, an effect of the cooling is clearly evident throughout the entire range of the imposed mass flow rate. A rate of change of the vanes temperatures was much higher for a small mass flow of the coolant and then asymptotically tended to a saturated state which was not fully reached during the present experiment. A difference in the vane temperatures between conditions without cooling and with a maximum mass flow of the coolant was approximately $150{ }^{\circ} \mathrm{C}$. It should be noted, however, that the coolant temperature was lower than required.

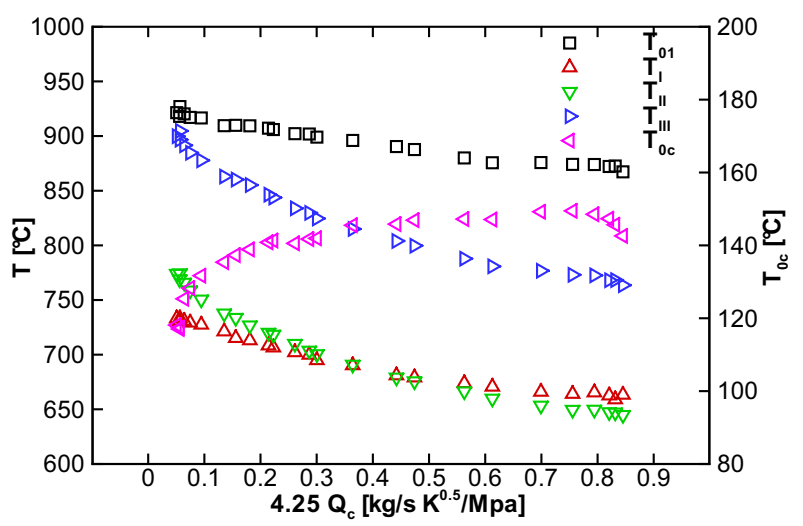

Figure 13. IGV-EC - the measured temperatures with respect to a variation of the coolant mass flow rate capacity.

\subsection{IGV segment with internal coolant delivery}

The tests on the IGV-IC segment were carried out for measurements with a constant exit Mach number $\left(M_{2, i s}=1\right)$ while varying inlet total temperatures. An evolution of the blade temperatures with respect to a change of the total conditions at the inlet is presented in figure 14. The same pattern in a distribution of the vanes temperatures was observed as for the previously tested configurations with the highest temperature indicated for the vane III and the lowest on the vane II. The observed temperature differences between the individual vanes grew almost linearly with an increase of the total temperature which further supports the assumption of spatially non-uniform heat conduction 
through the test section. For the highest attained temperature at the inlet $\left(910^{\circ} \mathrm{C}\right)$ a difference between the vanes II and III metal temperatures was again about $150{ }^{\circ} \mathrm{C}$.

The temperature of the coolant air measured in the vane cavity is also depicted in figure 14. It attained a maximum value above $450{ }^{\circ} \mathrm{C}$ while the temperature at the inlet to the combustion chamber was held nearly unchanged at $310^{\circ} \mathrm{C}$.

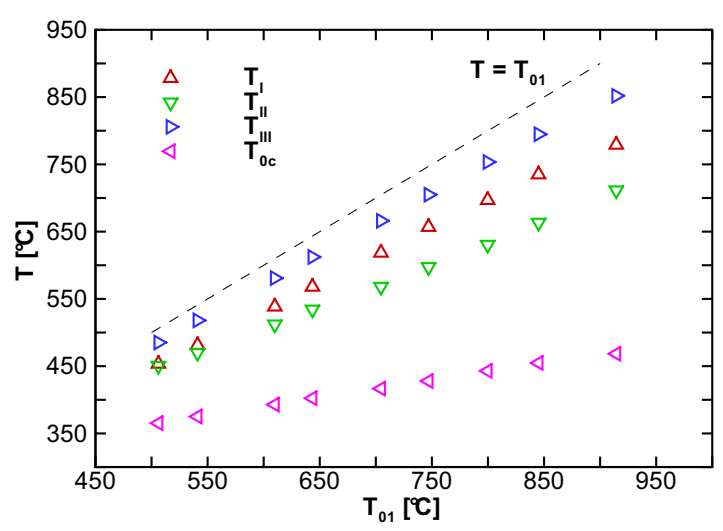

Figure 14. IGV-IC - an evolution of the blade metal temperatures with a variation of the inlet total temperature; $\mathrm{M}_{2, \text { is }} \approx 1$.

A temperature drop obtained for the vane III was about $60{ }^{\circ} \mathrm{C}$ when the highest inlet temperature about $910^{\circ} \mathrm{C}$ was imposed. It is a significantly lower value then one reached with the IGV-EC arrangement. Nevertheless, the coolant temperature in the present case was also much higher $(\approx$ $450{ }^{\circ} \mathrm{C}$ ) which in turn resulted in a reduced cooling efficiency.

The other two vanes, labelled as I and II, showed somewhat lower metal temperatures compared to the vane III (figure 14), but it was likely only due to their overall lower temperature level as similarly indicated for the IGV-NC and IGV-EC experiments (figure 12 and 13).

\section{Conclusion}

The paper presents results of a work focused on a design and verification of a novel cooling system for the inlet guide vanes (IGV) of small turbine engines. The proposed cooling concept was firstly verified using numerical simulations and later tested during an experimental campaign.

The cooling air was brought to the hollow vane from a space between the combustion chamber and the outer diameter of the IGV and then discharged back to the main flow through seven holes uniformly positioned along the vane height in the rear part of the pressure side.

The performed flow simulations, coupled with a heat transfer to the solid parts, indicated a significant reduction of the solid temperature of the entire vane and particularly in the trailing edge region. An achieved drop of the temperature was about $80^{\circ} \mathrm{C}$ for nominal flow conditions with approximately $1.5 \%$ of a total amount of the air considered for cooling.

The experimental results obtained for an IGV quarter segment with the internally delivered coolant (a real engine configuration) showed a somewhat lower cooling efficiency than the one predicted by the numerical simulations. The measured temperature drop was approximately $60{ }^{\circ} \mathrm{C}$ when the flow parameters close to nominal conditions were prescribed. It should be noted, however, that the measured coolant temperature was a little bit higher than one assigned in the prediction $\left(460{ }^{\circ} \mathrm{C}\right.$ vs. $\left.410{ }^{\circ} \mathrm{C}\right)$. On the contrary, when the externally delivered coolant with a desired mass flow and a comparable temperature were considered, a measured temperature drop of the solid reached a similar value as predicted by the numerical simulation.

In general, the presented results proved a feasibility of the proposed cooling concept adopted for a small turbine engine. An extended life span of the cooled IGV should therefore be expected while maintaining the high temperature at the inlet. Additional tests on a real engine should be however performed in order to verify the concept with more realistic (heat transfer) boundary conditions and with a longer operational period.

\section{Acknowledgement}

Presented results were obtained during the work in project ESPOSA - Efficient Systems and Propulsion for the Small Aircraft, GA284859 co-funded by European Commission within $7^{\text {th }}$ Framework Program.

\section{References}

1. F. Bayley, A.R.C. Technical Report 3110, Aeronautical Research Council (1959)

2. R. Bunker, Turbine Engine Film Cooling Design and Applications, in VKI Lecture Series, Film Cooling Science and Technology: State-Of-The-Art Experimental And Computational Knowledge (Von Karman Institute for Fluid Dynamics, 2007)

3. P. Straka, R - 5052, VZLU - Aerospace Research and Test Establishment (2011)

4. P. Straka, R - 5074, VZLU - Aerospace Research and Test Establishment (2011)

5. R.A. Dennis, ed., The Gas Turbine Handbook (U.S. Department of Energy-National Energy Technology Laboratory (NETL), 2006), http://www.netl. doe.gov/research/coal/energy-systems/ turbines/publications/handbook

6. A. Hellsten, Ph.D. thesis, Helsinki University of Technology (2004)

7. Edge - Theoretical formulation, ver. 5.2, FOI (2010) 